\title{
Pictures Revisited: A Traditional Vehicle in Enhancing Young Learners' Vocabulary
}

\author{
LEE BEE CHOO (Corresponding Author) \\ School of Languages, Literacies and Translation \\ Universiti Sains Malaysia \\ beechoo_lee@usm.my \\ AMBIGAPATHY PANDIAN \\ Faculty of Language and Communication \\ Universiti Malaysia Sarawak \\ pambigapathy@unimas.my \\ SOUBA RETHINASAMY \\ Faculty of Language and Communication \\ Universiti Malaysia Sarawak \\ rsouba@unimas.my
}

\begin{abstract}
The dire state of high illiteracy rate in the English language among Malaysian students speaks for the need for efficacious language learning approaches, expressly to augment learners' vocabulary knowledge which is deemed the foundation of language development. This paper overviews the various measures pictures have been traditionally utilised for successful vocabulary learning and it surmises that pictures have been gainfully employed in picture storybooks and flashcards, as well as enlarged posters and imagery creation for effective vocabulary acquisition. As aptly put by Ryan (1993, p.1), "Carefully selected pictures can be a catalyst giving rise to the production of thousands of words." Therefore, this paper aspires to firstly, appraise the diverse ways pictures have been tapped for language development and secondly, to examine the effectiveness of the methods and pose recommendations. Leveraging on the resources and previous research findings of researchers renowned in this field as a reference, this paper focuses largely on related studies by Malaysian researchers to render it relevant to Malaysian learners. It is hoped that this review does not only furnish one with consequential insights into vocabulary development for young learners that can be applied in our Malaysian classrooms for effective teaching and learning but serves to rejuvenate interests in pictures as a means to an end where vocabulary learning is concerned. The prevailing perspective is to acknowledge the richness and scope of pictures, as well as its versatility and to capitalize on them advantageously for utmost benefits in Malaysian classrooms.
\end{abstract}

Keywords: pictures, vocabulary learning, young learners, Malaysian classroom

Published online: 31 October 2019

To cite this article: Lee, B. C., Pandian, A., Rethinasamy, S. (2019). Pictures Revisit: A Traditional Vehicle in Enhancing Young Learners' Vocabulary. International Journal of Language, Literacy and Translation 2(2), 54-74. https://doi.org/10.36777/ijollt2019.2.2.027

To link to this article: https://doi.org/10.36777/ijollt2019.2.2.027 


\section{BACKGROUND}

Irrespective of disciplines, all research academic activities rely on the expansion of research based on existing knowledge. Hence, the relevance of literature reviews as a research approach. As elucidated by Tranfield, Denyer and Smart (2003), reviewing literature is a systematic course of action to gather and synthesize previous findings, thus generating a base for advancing knowledge and expediting theoretical evolution. This also contributes towards providing evidence on a meta-level, as well as identifying research gaps that are vital for the expansion/creation of conceptual and theoretical frameworks.

In the past researchers have promoted pictures or images as being exceedingly fitting for language learning, particularly in the teaching of a variety of English language components such as vocabulary. For instance, specialists in research-based instructional strategies, Joyce, Weil and Calhoun (2015) advocated specifically that pictures be used for vocabulary acquisition among children as it has been proven to be highly effective. Providing further support to picture power is Cohen (2012) who stressed that images, as a core element of cognitive processing, would greatly benefit learners in terms of acquiring the meaning of the lexical items, remembering them, as well as retaining the knowledge over time.

Lexis is arguably one of the most important, if not the most important component in language acquisition. Therefore, vocabulary instruction is the key to improved language proficiency and this is further extended to language skills and academic achievement, as irrevocably highlighted in many studies pertaining to second language acquisition (McKeown \& Beck, 2014; Neuman \& Wright, 2014; Su, Thiebaut de Schotten, Zhao, Song, Zhou, Gong, McBride, \& Ramus, 2018). Collective research findings indicated a similar consensus among Malaysian researchers that ties vocabulary knowledge to successful second language acquisition (Ashrafzadeh \& Nimehchisalem, 2015; Abdul Razak \& Md Yunus, 2016; Tan, 2016; Varatharajoo, 2016).

However, imparting vocabulary knowledge to learners remains not only a highly challenging task but is also a complicated one, particularly so when it involves young learners (McKeown \& Beck, 2014) but given how vocabulary input can determine early L2 success or failure, it seems only right to channel more attention to this area. It is quite unfortunate in Malaysia that vocabulary teaching is largely considered secondary in mainstream language teaching with grammatical structures and syntactic patterns finding more favour in the current primary curriculum framework (see DKSP, 2017). This is more so when approximately more than half of Malaysia's young citizens have been pronounced illiterate in the English language even though having completed six years of primary education (Hazita, 2016); a disastrous augury for Malaysian society. Immediate actions need to be taken to further enhance language development, particularly within the realm of vocabulary acquisition.

This paper calls for a revisit on pictures as a language learning instrument seeing it is a traditionally preferred tool in the Malaysian classrooms with young learners. Therefore, the paper firstly aims to review the various manners pictures have been used and secondly, to examine the effectiveness of the respective methods. Previously, images have been used as enlarged posters and in picture storybooks, and as well as for imagery creation and in flashcards. Calhoun (1999) primarily examined vocabulary acquisition and writing via enlarged pictures using her Picture Word Inductive Model (PWIM) instruction while Sol,'s (2008) study on images and memory strategy using picture storybooks showed that linking lexis to an image or items in the image amplifies memory efficiency. Additionally, Cohen $(2009,2012)$ examined the 
effectiveness of imagery creations on second graders and college students respectively and her work further highlighted the benefits of using imagery for vocabulary development at all instructional levels. Flashcards have also been hyped as an effective instrument for intentional learning, supplementing incidental learning (Nation, 2006; Schmitt, 2008).

Specifically, the purpose of this paper is to afford important insights into vocabulary development for young learners via images that can be applied in our Malaysian classrooms for effective teaching and learning by fabricating and synthesizing various past and current research efforts.

\section{METHODOLOGY}

While being selective of studies that would comprise a worthwhile contribution, this paper generally adheres to guidelines pertaining to systematic review to appraise and construe research evidence pertinent to a particular inquiry often broached in a cause-and-effect structure (Davies, Mengersen, Bennett, \& Mazerolle, 2014; Glasziou, 2001). As stated by Walsh and Downe (2005), systematic review "is a robust way of comparing quantitative research and proceeds according to well-determined steps, which include statistical analysis of the pooled results of studies. This statistical analysis is more accurately called meta-analysis, although this phrase has become interchangeable with systematic review" (p. 204-205). Typically, the approach synthesizes and compares evidence of effect systematically of specific research areas on quantitative studies (Snyder, 2019) that design to assess what has been recorded and eventually to consolidate and summarize the findings.

Relevant literature consisting of a summary of key sources within specific conceptual categories were first identified and evaluated for appropriateness prior to retrieval within the boundaries of various inclusion and exclusion criteria relating specifically to the implementation of pictures/images in classrooms for vocabulary/language learning. The various methods pictures can be employed were first identified and narrowed down based on responses gathered from 4 primary school teachers who were interviewed on the employment of pictures in the classroom. Retrieval of relevant data was then carried out via academic databases (e.g., Research Gate, Google Scholar, JSTOR, ProQuest and Directory of Open Access Journals) with searches conducted using keywords like pictures/images and vocabulary/language learning/acquisition. More specific keyword combinations include flashcards, picture storybooks, big books, imagery creation, posters, PWIM and vocabulary/language learning/development.

Since it is simply not possible to review every single article that could be relevant to the topic, the researcher generally seeks to discern probable applicable research findings that possess implications for the topic. Nevertheless, while covering broad topics, the inclusion and exclusion criteria were dutifully applied in the research process to ascertain the paper's relevance to a greater extent. Selected studies include those conducted on mainly primary school pupils that looked at how images employed as flashcards, posters and picture storybooks, and in imagery creation impacted vocabulary learning in English and other languages as well. Another inclusion criterion is the affective factors such as interest and enthusiasm, and motivation as those factors are highlighted in studies on children. This excluded studies conducted on adult/tertiary learners, as well as those that utilized pictures in other modes. Additionally, those studies that focused on specific language skills such as writing, listening, speaking and reading were ruled out in accordance with the objective of the paper. Another criterion further stated that only 
experimental studies were selected which led to the exclusion of studies featuring the opinions/perceptions of learners/teachers on the impact of pictures on vocabulary acquisition. Also, the review was extended to cover less current studies to augment the comprehensiveness of the literature base. However, such articles were not expounded on, rather they were referenced. The articles reviewed were mostly published after 2010 .

\section{THEORETICAL FOUNDATION}

The notion that pictures are remembered better than words is first mooted, with documented evidence, by Kirkpatrick (1894, as cited in Kahana, 2012). Memory for pictures is collectively accepted to be greater than memory for words (Paivio, 1990), for pictures are often universal and not constrained by knowledge of a specific language. The superiority of pictures over words gives rise to the term, Picture Superiority Effect (PSE) (Shepard, 1967) with theorists such as Nelson, Reed, and McEnvoy (1977) and Paivio (1971) agreeing that PSE is the result of greater conceptual processing for pictures than for words.

At large, PSE is deemed a reliable phenomenon that can be reformulated, in particular, its amazing performance in picture recognition. However, admittedly constraints exist in its limiting conditions. A case in point is the possible reversal or the abolishment of picture superiority via manipulations of encoding demands (Durso \& Johnson, 1980), though Weldon and Roediger (1987) stood firm that PSE is "relatively insensitive" to varying retrieval conditions. Further explorations of the marginal conditions in later years gave rise to theories that ascribe the PSE's effects on conceptual and perceptual processing in terms of encoding tasks and retrieval conditions (Jacoby, 1983).

Based on the fact that pictures are generally more diverse and distinct in its facets, it has been hypothesized that memory effect can be attributed to perceptual features. As the process of remembering is broadly envisaged as an engagement of encoding, storage and retrieval, PSE is viewed as aligned to theories that emphasis encoding and storage processes, as well as retrieval factors as the points of effects. Prominent theoretical accounts proposed are Paivio's (1971) dualcoding theory (DCT), Nelson's (1979) sensory-semantic model (SSM) and the principle of transfer appropriate processing (TAP) as suggested by Roediger (1990).

\section{DUAL-CODING THEORY}

The notion that perceptual form possesses a strong influence on pictures superiority is elaborated in Paivio's (1971) dual-coding theory which claimed that pictures, eliciting a verbal code and an image code, are dual coded and this has a definite advantage over words which encoded verbally, are single coded. Based on Paivio's (1971) DCT, vocabulary acquisition used both or either of the verbal and nonverbal cognitive processes and human cognition is deemed able to handle language together with nonverbal objects and event simultaneously. Paivio (1986) also stated that the language system does not only concern linguistic input and output in the form of speech and writing, but also serves as a symbolic purpose to nonverbal objects, events, and behaviours and that this dual functionality has to be accommodated in a representational theory.

In learning, it is assumed that two distinct and separate systems exist to serve human memory and cognition (Paivio, 1986). One system deals with language in the form of verbal information such as printed words, speech sounds and motor feedback from writing while another processes 
nonverbal information such as pictures or objects, environmental sounds and motor feedback from the physical exploration of objects. Perfectly capable of functioning separately, they also function together in a state of "interconnectednes" and complements each other by which representation in one system can activate those in the other, thus enhancing recall (Al-Seghayer, 2001). On the other hand, when the systems function independently, both pictures and words can independently activate nonverbal or verbal memory codes that in turn are indirectly activated by imagery and verbal encoding tasks (Al-Seghayer, 2001).

Paivio's DCT basically identified three types of information processing; the first type is the representational, a direct activation of verbal or nonverbal representations while type 2 is referential which is the activation of the verbal system by the nonverbal system or vice-versa, and the third type is associative processing which is an activation of representations within the same verbal or nonverbal system (see Figure 1).

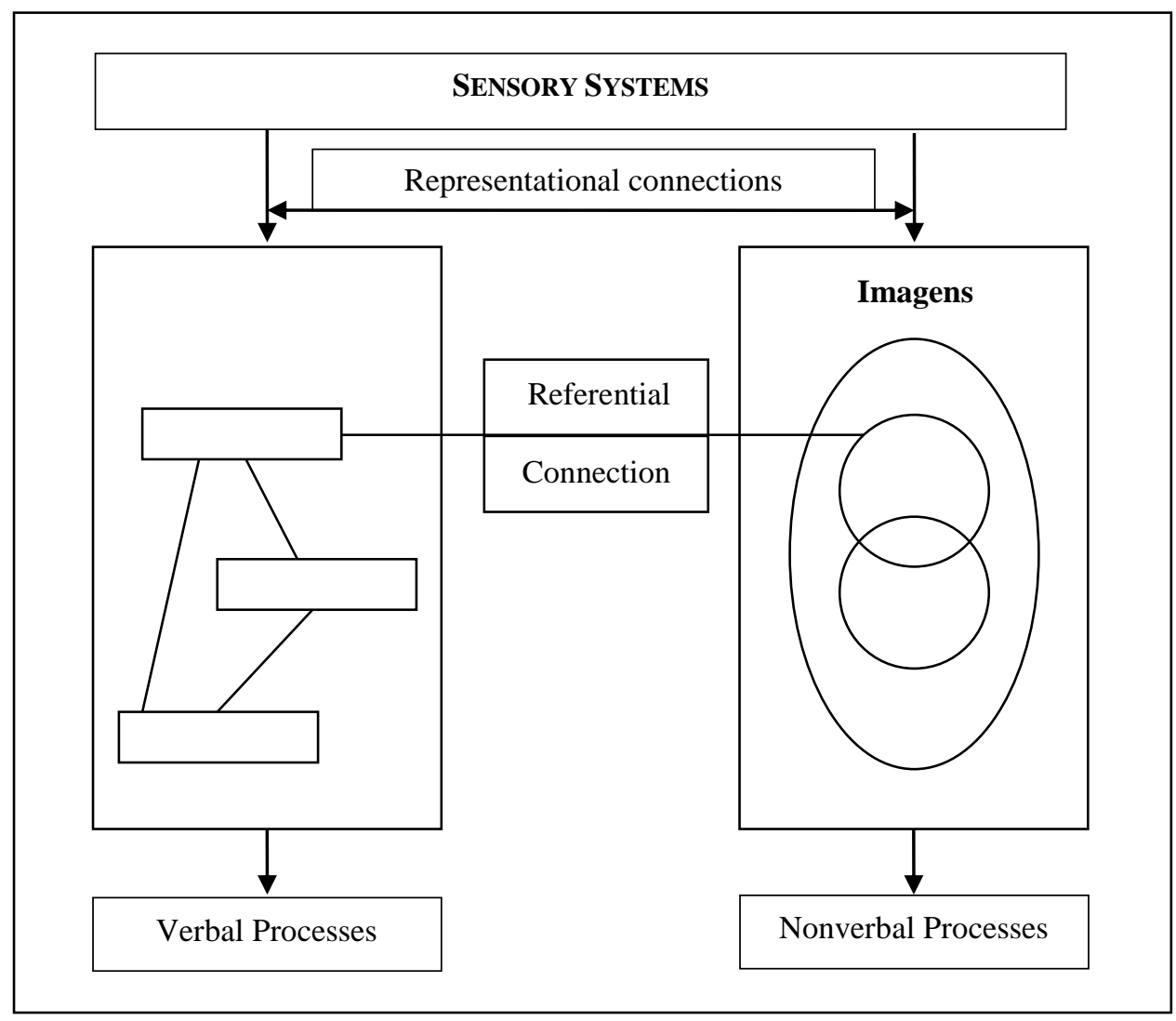

Figure 1. Information Processing

This work is adapted from Paivio's Dual-Coding Theory (p. 65), by A. D. Paivio, 1971, New York: Holt, Rinehart \& Winston. Imagery and verbal processes.

As shown in Figure 1, there are two different types of representational units; one being imagen of mental images and the other is logogens of verbal entities. Imagens refer to images or picture-like representations while logogens are linguistic information such as words and sentences. Based on Paivio's dual-coding model, it can be deduced that dual coded information 
is simpler to retain and to retrieve as compared to monocoded information. Words or logogens are processed much faster than recalling the information through synchronous processing as opposed to the sequential access of information in the verbal system (Paivio, 1971). Learners may select the manner of information processing suitable for their needs and learning style. This flexibility in choice helps in their learning, and therefore when presented with multiple ways of learning each of the learning method complements the others to enhance learning.

\section{SENSORY-SEMANTIC MODEL}

Another theory that links storage to perceptual form is Nelson's (1979) sensory-semantic model. SSM conceives of a semantic store where common codes embody connotations of events, regardless of the input form. Advancing Paivio's DCT on the superiority of a dual-coded model to a single-coded one, especially where young learners are concerned, SSM claims that sensory and semantic codes gain access to phonemic information differently. The model works on the presumptions that both sensory and semantic codes can be activated for pictures and words but with a difference in the relative order of access to phonemic information for the two forms of representation. In the case of pictures, phonemic access is indirect with semantic processing occurring before name codes becoming accessible. As for words, with phonemic access being direct, the necessity doesn't arise for earlier semantic processing. In a literal sense, pictures have to be meaningfully understood before labelling can take place. Conversely, for words, semantic access is not a prerequisite for the activation of phonemic codes.

Nelson, Reed and Walling (1976) further opined that high levels of either schematic or conceptual similarity will lead to disruption among serial ordering of the pictures, thus resulting in either eradicating or reversing the classic pictorial superiority effect. In short, no consistent effects are recorded where high levels of conceptual similarity among the labels for the pictures are found. Additionally, label similarity results in disrupted performances, particularly when the tasks necessitate either serial reconstruction or serial recall of the order of the two types of stimuli (pictures and words). This is irrespective of other variables, hence, justifying the apparent necessity of labelling stimuli in serial order.

Nelson's sensory-semantic model differs from the Paivio's dual-coding theory in that the relative order of access to phonemic information is different for both sensory and semantic codes (Nelson, et al., 1976) which proves to be a contrast from the dual code hypothesis with a levelsof-processing conceptualization. However, both dual-coding theory and sensory-semantic theory illustrate a description of picture superiority based on differences in encoding between pictures and words (see Figure 2) 


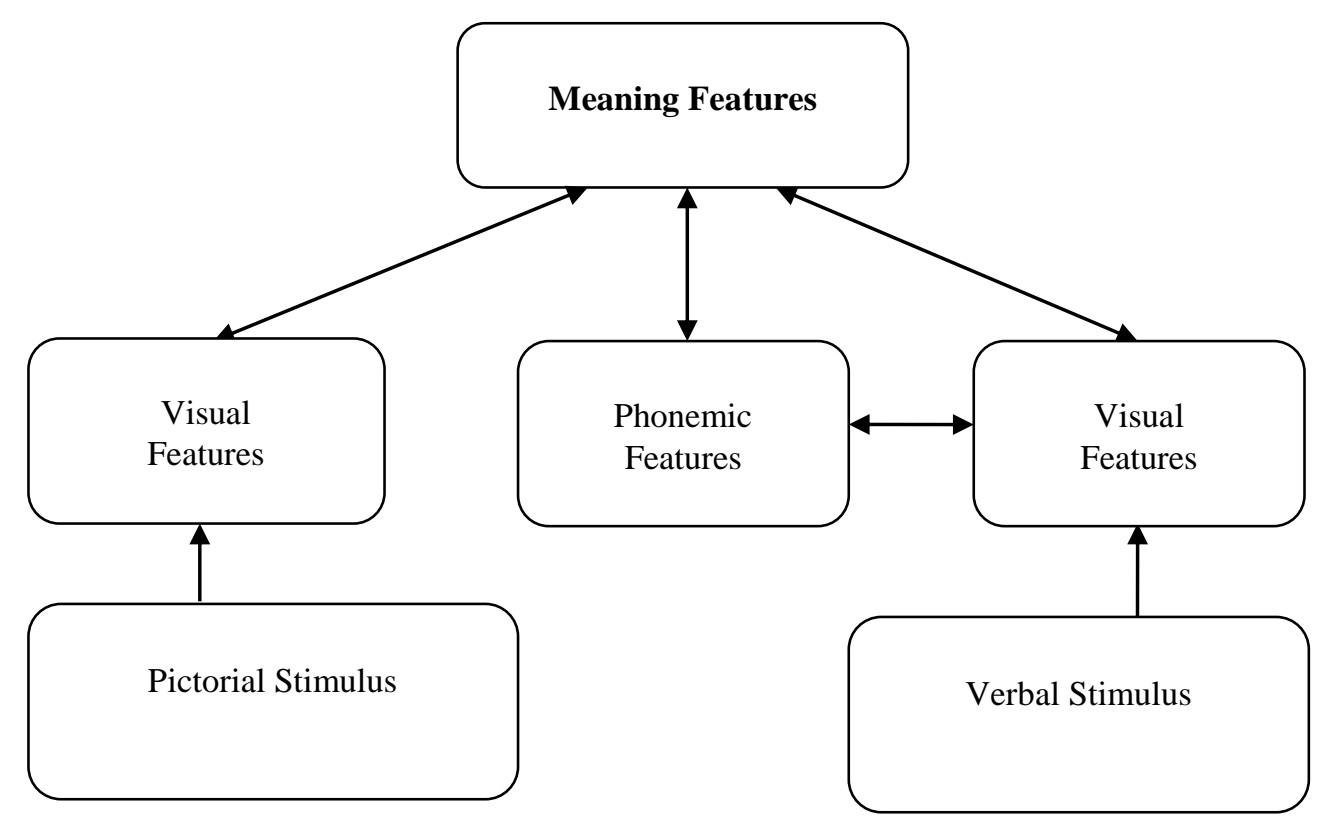

Figure 2. Picture and Word Encoding

This work is taken from "Human learning and memory" by D. L. Nelson, V. S.

Reed and C. L. McEnvoy,1977, Journal of Experimental Psychology, 3, p. 486.

As illustrated in Figure 1, the processing of pictures and words sets to activate certain features or codes depending on differing stimulus one is exposed to.

Unlike verbal stimulus, the meaning features for picture stimulus can be accessed with the bypassing of the processing of phonemic features, an assumption that has received tremendous support from Nelson and Brooks (1973), Nelson and Reed (1976) and Potter and Faulconer (1975). In discrete stimulus tasks involving the presentation of words without the benefit of meaningful context, semantic access is often achieved after some amount of processing of phonemic features (Nelson, Brooks, \& Borden, 1974). Hence, it can be deduced that within the sensory-semantic model there exists a distinction between the processing features and the activation of mnemonic codes as an end product of processing those particular features. Additional processing devoted to any features simply increases the likelihood that they will be reintegrated into a functionally effective code. Finally, it is assumed that the amount of processing directed toward specific features can be controlled by the task requirements (Craik $\&$ Tulving, 1975).

\section{TRANSFER-APPROPRIATE PROCESSING}

The picture superiority effect is further elaborated through conceptual processing in the transferappropriate processing (TAP) approach as proposed by Roediger (1990). According to Weldon and Roediger (1987), TAP accounts for picture superiority by an interaction of encoding and retrieval; pictures are more likely than words to access meaning during encoding. The superior performance for pictures on recall and recognition tasks, as explained by Weldon and Roediger (1987), would be more obvious on tasks that require conceptual retrieval. 
TAP was proposed as a principle of memory processing based on the rationale that humans are naturally swifter in performing tasks that they have been exposed to previously. From the perspectives of Tulving (1979), it complimented encoded representations of properties of stimuli and their context. TAP's initial framework stressed on explicit memory and how it was facilitated by the degree of overlap between processes engaged during first exposure and second exposure; the greater the overlap, the greater the performance. Subsequently, as witnessed in the work of researchers such as Srinivas (1996), Roediger and Blaxton (1987), among others, implicit memory duly made its way into the framework.

According to Roediger (1990), explicit measures of human memory such as recall or recognition is deemed a reflection of past conscious reminiscence whereas, for implicit tests of retention measure transfer, known also as priming, a conscious recollection of past experiences is not a prerequisite to perform. Substantial differences are recorded between explicit and implicit measures; pictures are remembered better than words on explicit tests but words produce more priming than do pictures on severe implicit tests. Hence, deliberations of the differences and dissociations between implicit and explicit memory were embodied and adjusted in the applications of TAP within the implicit memory domain.

Empirical evidence attained in an experiment conducted by Weldon and Roediger (1987) highlighted the existence of dissociations between priming tests in normal subjects which are in good agreement with the TAP approach to explaining dissociation (See Figure 3).

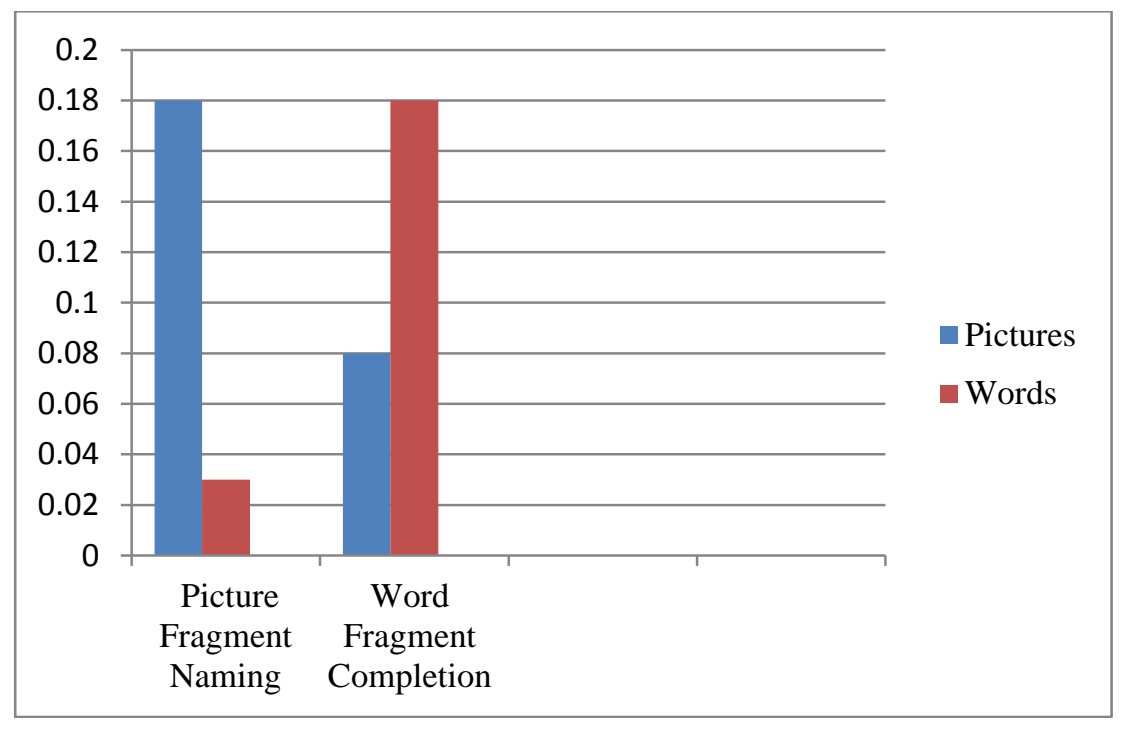

Figure 3. Encoding \& Retrieval

This work is taken from "Altering retrieval demands reverses the picture superiority effect" by M. S. Weldon and H. L. Roediger, 1987, Memory \& Cognition, 15, p. 277.

As appeared in Figure 3, there is a striking dissociation between two implicit tests in that pictures produced greater priming than did words on the picture-fragment naming test, and reversely so for the word-fragment test. Data obtained are found to be in tandem with the TAP approach in accounting for the dissociations between explicit and implicit tests found in normal subjects as a function of various independent variables (Roediger, Weldon, \& Challis, 1989; Roediger \& Blaxton, 1987). Thus, the TAP approach also accounts for dissociations between 
explicit tests (Morris, Bransford, \& Franks, 1977) as well as implicit tests (Roediger, Srinivas \& Weldon, 1989).

In sum, TAP accounts for picture superiority by an interaction of encoding and retrieval; pictures are more likely than words to access meaning during encoding. Also, the superior performance for pictures on recall and recognition tasks will be more obvious on tasks that require conceptual retrieval.

\section{PICTURES AS VEHICLES}

L2 research-validated strategies involving the use of pictures are plenty. As claimed by certain researchers (Carpenter \& Olson, 2012; Joyce, Weil, \& Calhoun, 2015; St. John \& Vance, 2014), pictures, if correctly exploited, is an important vehicle for more effective language development. This paper looks at studies that employed pictures as enlarged posters and flashcards, and in picture storybooks and image creating in language learning.

\section{PICTURES STORYBOOKS}

A picture storybook is a written work that deals with two distinctive art forms; text and illustrations. Apart from the notion that human memory for recall and retention for images is by far superior to memory for other modes (Paivio, 1971), pictures are also viewed as an effective vehicle in the peg-word system (Sol, 2008), a memory strategy that links lexis to the picture or items in the picture, thus amplifying memory efficiency. In addition, in Ausubel's (1978) study pictures were considered first-rate advance organizers for schema activation and construction, thus potentially benefiting the cognition process in language acquisition.

Picture storybooks have traditionally been used to promote language development in children through activities such as storybook reading or reading-aloud, shared reading or extensive reading among others. Earlier studies (e.g., Brabham \& Lynch-Brown, 2002; Nagy, Anderson, \& Herman, 1987; Wasik \& Bond, 2001) have advocated reading for effective language and literacy development in young children and similarly, Robbins and Ehri (1994) found storybook reading highly useful for lexicon expansion and enlargement of young learners' conceptual knowledge. Additionally, Trivette and Dunst (2007) had previously recommended the activity be implemented either as interactive or dialogic reading with vocabulary-fostering techniques such as the use of keywords and first language being taken into account. In interactive reading, adults read to the children and utilize the pictures in the storybook to get them engaged in the story. As for dialogic reading, children "read" the storybooks with the help of adults and the storybook pictures. It is to be noted that either technique capitalizes on pictures to facilitate the activity which reinforces the prominent role pictures procure in picture storybooks.

Closer to home, picture storybooks have long been used as a tool for both intentional and incidental vocabulary instruction in the Malaysian classroom. A more current study by Adlina and Normah (2018) on Malaysian picture storybooks as reading materials for young learners concluded that pictures in storybooks assist young learners to connect to the text as part of the story for the pictures build meanings and furnish the text with cohesion, particularly in the representation of the story's characters. The results of their study showed that picture storybooks (90\%) possess higher narrativity compared to chapter storybooks (40\%). On the other hand, an experimental study was conducted by local researchers (Tan \& Parimala, 2014) to compare the effects of contextualized storytelling with the text with picture stimulus approach on 90 primary 
5 pupils in Pulau Pinang. Although findings indicated better performance by subjects in contextualized storytelling than those in picture stimulus, Tan and her colleague advocated guidance on interaction with the pictures for improved understanding of text narratives which is in support of findings by Wang (cited in Huang, 2006). Also, Aizan and Annamaria (2008) recorded pedagogical significance resulting from using Big Books in Malaysian primary classrooms. Drawing on transcript data there was a notable increase in pupils' interest and motivation that led to improved interaction structures and expanded learning opportunities in the classrooms. This supports the findings of previous local research on primary pupils that promoted pictures as an effectual tool to help pupils to focus on key details, as well as aid in following the storyline (Ghanaguru, Liang, \& Kit, 1998).

Past research findings have consistently painted picture storybook as a worthy vehicle in boosting language development for pictures do not only capture learners' attention and make interesting what could otherwise be a lengthy and unappetizing piece of text, particularly to the less adept readers, they also play a variety of roles in storybooks helping to augment vocabulary building among young learners by means of sustained creative and effective lexical prompts. Semantic development is also fostered via focusing on the pictures during a storybook reading activity. As such, teachers may find it worthwhile to try out this tool in their classrooms.

\section{FLASHCARDS}

Nation (2006) and Schmitt (2008) both opined that incidental learning is hardly sufficient and a supplementary tool such as flashcards is necessary to provide intentional learning. The value of flashcards seems to lie in its ability to utilize L1 to initiate form-meaning link (Schmitt, 2008; Nation, 2001), thus facilitating not only simple recognition but recall as well and further advancing the acquisition of word depth. According to Oxford and Crookall (1990), flashcards are a semi-contextualizing technique that uses a pairing of words or definitions coupled with visual imagery.

"A cardboard consisting of a word, a sentence, or a simple picture on it", flashcard as defined by Baleghizadeh and Ashoori (2011, p. 2). Flashcards evoke transition from short-term to longterm memory (Nakata, 2008) through its requirement of the learner to search for and type the word during retrieval, unlike the traditional paper cards. Presuming learners create the flashcards themselves, the need to identify target words is, itself a prerequisite to learning (Nation, 2001). Furthermore, when learners are required to organize the written words meaningfully, the process only serves to deepen and strengthen their vocabulary knowledge; writing helps one to recall (Nation, 2006). Dodigovic (2013) who compared the effectiveness of flashcards made by teachers and those made by learners themselves found the latter more effective.

Frequently employed for intentional vocabulary learning, flashcards, or word cards as it is sometimes termed, is claimed to be a variation of word lists, an early decontextualizing technique often commended for language learning particularly during the era when Grammar Translation Method dominates. Pitted against word lists for effective vocabulary learning in earlier studies, flashcards won hands down (Schmitt \& Schmitt, 1995; Mondria \& MondriadeVries, 1994). Later studies that similarly favoured flashcards over wordlists in terms of vocabulary learning include those conducted by Bruton (2007), Erten and Tekin (2008), and Tang and Nesi (2003), among others. Expounding on the benefits of word lists, flashcards is considered to be a more interactive and fun tool for classroom teaching and learning activities. Examples of past research efforts include Culyer's (1988) who found that flashcards benefit poor readers in terms of word recognition and that it could also be used effectively for teaching 
propositions, articles, sentence structures, tenses, and phrasal verbs (Palka, 1988). As for Tan and Nicholson (1997), both advocated flashcards as a medium for improved comprehension and reading speed. Superior vocabulary scores from tertiary students who studied with the aid of paper-flashcards were also recorded as compared to those who studied without such aid (Komachali \& Khodareza, 2012).

In the Malaysian context, studies on the employment of flashcards for vocabulary acquisition among local primary pupils documented positive findings, thus encouraging the use of flashcards in classroom learning. Phang's (2019) current experimental study on the effects of flashcards as a traditional visual aid on English vocabulary learning among Form 1 students has produced positive findings. Flashcards were also highly recommended for effective vocabulary acquisition in Malaysian primary classrooms by Iliyasu, Lee, Dikko and Abba Aji (2016) who suggested that teachers incorporate them into activities with subsequent follow-up activities for evaluation purposes. There was also a study conducted on mind-mapping and use of flashcards in vocabulary development among 30 primary 5 pupils (Meena, 2014). Analyzed pre- and post-test scores indicated higher positive findings when both strategies were combined as compared to singular employment of the strategies, thus indicating that a combined approach may be more effective than a singular one. Interest in this approach has also extended to a study conducted on Hijaiyah literacy via flashcards for effective literacy development on pupils in Selangor and Federal Territory. Muhamad Zahiri, Siti Salwa, Noriza, Faridah and Mislinah (2016) promoted the use of flashcards for aiding weaker learners to recognize letters and learn vocabulary items more effectively.

Paper-based flashcards studies on language learning have generally advocated the effectiveness of the approach. However, in recent years there is a noticeable deviation of interest from the traditional paper-based cards to digitized or electronic flashcards and not necessarily targeting only young learners (Dodigovic, 2013; Hung, 2015; Nikoopour \& Kazemi, 2014), denoting a present-day interest in an age-old classroom tool mainly employed for vocabulary learning with young learners. Hung (2015) and Dodigovic (2013) utilized free online tools, Study Stack and WordCham, to generate and customize digital flashcards for their respective studies while Nikoopour and Kazemi (2014) paid for a customized website for similar purposes. All three reported positive findings of the effectiveness of the instrument in enhancing vocabulary knowledge.

Based on cumulative research findings, flashcards are largely found effective for language learning in the classrooms. Though flashcards have also been criticized for prioritizing memorization, rather than comprehension (McCullough, 1955), by far and large flashcards are found effective in augmenting pupils' vocabulary knowledge. Largely advocated for their practicality and comparative ease in classroom usage in that extensive language practice can take place without great ado or at a high cost, both paper-based and digitalized cards can be constructed economically without much difficulty. Apart from enhancing vocabulary knowledge retrieval and retention, learners also experienced substantial increased engagement and motivation to learn via the activity which is generally regarded as fun activity by learners regardless of age. With the current trend displaying an onslaught of technology, there indicates an evolvement of flashcards into digitized form, either online or mobile. Hence, flashcard is noteworthy as an effectual tool for language learning and development as the positive findings outweigh the criticisms. Additionally, we should be mindful of the variations that can further elevate its effectiveness. Take, for instance, the notion of having pupils creating the flashcards themselves instead of opting for store-bought ones (Dodigovic, 2013; Nation, 2006) and card 
design effectiveness (Dodogovic, 2013). Not to be dismissed is the notion of combining flashcards with other learning methods for greater teaching and learning experiences as discovered by Meena (2014) in her study.

\section{PICTURES AS POSTERS}

With the edge pictures are reckoned to possess over lexis in language learning, they have also been resourcefully utilized as enlarged posters for classroom learning. Calhoun (1999) designed Picture Word Inductive Model (PWIM), a model of teaching, specifically to teach vocabulary and writing via posters. Fundamentally, "PWIM is an inquiry-oriented language arts strategy that uses pictures containing familiar objects and actions to elicit words from children's listening and speaking vocabularies." (Calhoun, 1999, p. 21).

Joyce, Weil and Calhoun (2015) in their book Models of Teaching $\left(9^{\text {th }}\right.$ Ed.), deemed PWIM to be the core of some very effective curriculums that serve as a literacy programme that is not only targeted at kindergarten and primary students but is also fitting for older novice readers and writers in secondary and high school, as well as adult learners. Its ability to assist learners to develop large sight vocabularies through the natural ways for children to approach the learning of a language account for much of its success as a model of teaching. On the practical side, pictures are also affordable and are easily sourced.

PWIM employs an integrated language arts approach to literacy within which lies multimodal activities (Calhoun, 1999). By incorporating inductive thinking and concept attainment (see Step 2 and 5 respectively) as well as explicit instruction in its model of teaching, learning and teaching is fluid as one moves from rhyming words to developing word families/patterns, to composition strategies using words generated by students. Thus, eventually, you witness learners become fuller participants in language learning.

A full PWIM cycle ranges from two to four weeks with each PWIM session lasting approximately 15 to 20 minutes depending on students' needs and language development, and the teachers' objectives (Calhoun, 1999; Joyce, Weil, \& Calhoun, 2004); ultimately it is at the discretion of the teacher. Briefly, guided by the PWIM lesson structure (Calhoun, 1999, p. 23), the steps of PWIM are as summarized:

1. Select a picture.

2. Ask students to identify what they see in the picture.

3. Label the picture parts identified, say the word, write the word; ask students to spell the word aloud and then to pronounce it.

4. Read and review the picture-word chart aloud.

5. Ask students to read and classify the words (e.g., nouns, verbs, adjectives)

6. Read and review the picture-word chart

7. Add words, if desired, to the picture-word chart.

8. Lead students to think about the information on the chart and what they want to say about it.

9. Ask students to generate a sentence, sentences, or a paragraph about the picture-word chart.

10. Read and review the sentences and paragraphs.

Numerous studies on PWIM can be detected in recent years. While many of these studies focused mainly on the writing skills of junior high schools students, some examined PWIM's impact on young learners' vocabulary expansion. Examples of recent PWIM studies conducted 
include those by Nurani and Rosyada (2017) on communicative competence and Yuniati (2015) on writing recount text while Kurniawan and Andini (2015) looked at junior high school students' narrative writing skills via PWIM. All recommended the approach as an effective language teaching model based on positive findings in that PWIM has effectively helped subjects to improve on the various language skills. Alternatively, Jiang (2014), Lee (2013), and Li (2011) Yurfalah (2014) carried out studies on how PWIM impacted learners' vocabulary acquisition. Both Jiang (2015) and Yurfalah (2014) recorded significant improvements in subjects' vocabulary knowledge following exposure to PWIM. Lee's (2013) subjects in the experimental group likewise performed better than those in the control group. As for Li (2011), his pupils' superior test scores and greater engagement in the classroom are testimonials of the effectiveness of the approach. Learners can make the referential connection with the object in the picture and identified the sounds associated with the image, thus maximising the use of sensory systems for language development. The merits of this approach rendered it commendable for effective language teaching and learning.

\section{IMAGERY CREATION}

Visual imagery is a research-validated strategy that has garnered substantial support as an effective metacognitive tool of supporting and enhancing vocabulary knowledge as well as assisting in the mastery of language skills (Anderson, 1971; Sadoski, Goetz, \& Kangiser, 1988). In "imagery strategy" pictures are strategically put to use to store and retain vocabulary items for a longer period (Hsiao \& Oxford, 2002), thus involving linking target lexis with existing vocabulary knowledge via imagery. As discovered by Anderson (1971), those who created mental images of what they read are found to have learned twice or trice more than those who read texts singularly. The creation of images in a learner's mind has the ability to prompt recall and retention as well as promote understanding of text materials (Sadoski, Goetz, \& Kangiser, 1988) and facilitate the formulation of inferences and categorization of information (Cohen, 2009).

Numerous studies carried out by Sadoski between 1983 and 1985 on the ability of learners from grade 3 to 5 to recall and retell the entire stories they have read provided empirical data on the existence of a positive correlation between possessing/creating an image of the story's highlight and the scores recorded for theme retelling and total retelling. Hence, indicating that images effectively serve as an avenue for the recollection of a story as a whole.

The approach requires learners to form a mental image of the target word or words. Help is extended to those who face difficulty in doing so; pictures or vivid descriptions of the word are provided. The aim is for the learner to possess an image of the target word and then to link the word to the mental image the learner carries in his or her mind. Here, the underlying rationale is the depth of processing hypothesis. Apparently how well a newly taught word is retained rests on the inherent features of the cognitive processes employed to process that information (Craik \& Lockhart, 1972) rather than how long the learner is exposed to that word.

Studies on imagery creation present evidence that this sub-memory strategy overall does positively impact learners' vocabulary learning performance (e.g., Cohen, 2009, 2012; Nemati, 2009; Vesely \& Gryder, 2007). Take for instance, Cohen (2012) who detected that imagery creation, especially when learners are asked to draw the images, increases the depth at which new words and their meanings are processed, due possibly to "having to attend to details they might otherwise overlook" (Armon \& Morris, 2008, p. 49). However, it also came to light that it is highly possible that learners will not be able to come up with a mental image every time as 
required, especially for abstract words. Hence, the effectiveness of imagery creation at augmenting vocabulary knowledge would be in tandem with how abstract the target words are.

It is worthwhile to mention that previous work on the effects of imagery creation and vocabulary enhancement has also explored the combo of imagery creation and picture presentation versus imagery creation only. The intervention with solely imagery creation requires the subject to imagine an image that illustrates the meaning of that particular lexis whereas the one with picture representation has an extra tool in the form of a visual cue. Cohen's $(2009,2012)$ experimental studies yielded interesting findings; scores for image creation + picture presentation were highest for younger learners (grade 2 and grade 3 to 5) while scores image creation only were highest for older learners (mean age 20.82 years). As such, it can be deduced that age can be an influencing factor in which type of intervention to implement.

A more current study on imagery technique was conducted by Tukimin, Nik Mohd Rahimi and Harun (2019) to examine the effects it has on Malaysian primary 1 pupils' Arabic vocabulary learning. Based on post-test scores, Tukimin and his fellow researchers concluded that the technique does not only aid in identifying letters and reading but help to improve pupils' writing techniques as well. Similarly, the experimental group in the study by Zaheidi and Adbi (2012) on how this strategy impacted EFL learners' English vocabulary acquisition outperformed the control group in test scores, denoting greater vocabulary acquisition after experiencing the imagery technique. As such, it can be recommended as a language teaching tool in the Malaysian classroom, targeting vocabulary development in particular.

Having said that, while considerable empirical evidence has pointed to effective vocabulary acquisition via imagery creation, it is only prudent to consider the manner imageries are created as well as the configuration of an image if the aim is to have the strategy more widely practiced. It is necessary to take note of the level of abstractness of the word and the age of learners as well. Particularly when dealing with young learners who might face difficulty creating images as they will not have much prior knowledge to lean on given their young years, thus their limited exposure. It would certainly be helpful to pay attention to how images can be created among young learners seeing the effectiveness of pictures in facilitating vocabulary learning and retention. Still, given the documented success of the techniques in enhancing vocabulary knowledge, it is a worthwhile endeavour.

\section{DISCUSSIONS \& RECOMMENDATIONS}

The actuality of utilizing images in the domain of education for young learners has long been accepted though it may not be as widely applied as previously. The potential contributions of this paper can be witnessed within the spectrum of effects of studies conducted over a certain period; the consistency of the effects, techniques employed and the theories supporting them, findings in varying contexts and limitations, among others. Implications of the reviews for picture related theories and classroom practice are substantiated by research findings with studies' parameters and limitations taken into account to evade over-generalization of results.

Overall, the analysis conducted on research findings of the various methods lends support to the respective theories as discussed above. Documented data also implied the success of these picture related teaching approaches in the classrooms within the stated parameters related to the design of the research (e.g. aims, instruments and time frame), research subjects (e.g. age and size of sampling), as well as methodology. In turn, the limitations give rise to callings for 
subsequent research on the topic to extend generalization beyond the studies' parameters. For instance, studies on flashcards can be extended to embrace older learners and to use self-made cards instead of store-bought ones as recommended by Dodigovic (2013) and Nation (2006) but yet to be tested in the Malaysian context. Alternatively, we can attempt integrative literature review; expanding the scope of papers reviewed on a diminished number of picture related teaching methods. Hence, leveraging on the current literature for further improvements.

The results of this review indicated that there were pedagogical as well as motivational effects of utilizing pictures in the various modes mentioned for subjects' vocabulary acquisition and general language learning. Notwithstanding the limitations that reflect the weakness of the reviews, the studies reviewed specifically looked at how the subjects were impacted in experimental studies with documented findings, thus making it possible for generalizations to be made on a specific cohort of subjects with regards to vocabulary and language learning. Furthermore, these studies can be adopted and sufficiently versatile to be adapted for future studies depending on the objectives of the researcher, undeniably a strength of the papers reviewed.

By revisiting pictures as a vehicle in its various roles for language learning and teaching, it is hoped that there will be renewed interest in this medium. Based on the collective strength of previous and more recent studies, picture, be it as part of a storybook or reinvented as enlarged posters and cards, or in an imagery state, has shown its worthiness as an effective vehicle for enhancing young learners' vocabulary knowledge expansion, as well as language learning and development. This is despite some critical comments that deemed pictures a distracter, sidetracking learners' attention from printed content and hence, hampering reading progress (Carney \& Levin, 2002) though Joyce, Calhoun (1999) and Weil and Calhoun (2015) remained convinced that all pictures, including decorative ones, can be used for vocabulary acquisition and writing. Hence, as mentioned earlier, in selecting pictures, one needs to take into account the objectives of the lessons and learners' age; suitability of pictures has to be in accordance to the needs of target learners. Also, it would help for teachers to provide sufficient guidance and supervision to ascertain that learners are kept suitably engaged throughout the lesson. Overall, as can be discerned, language learning in Malaysian classrooms for young learners can be enhanced with the employment of pictures, suitably so.

\section{CONCLUSIONS}

An enduring emphasis on achieving mastery in the English language in Malaysia's education blueprint gives rise to an inclination to be more attentive to the learning of the language other forms. Over the years, L2 teaching and learning may have gradually made headway with a discerning diverse school of thoughts; interestingly enough vocabulary knowledge has retained its significance to literacy development and mastery. Likewise, images have remained steadfast in its role as a vehicle for language learning despite being overlooked and undervalued at times, possibly due to encroachment of technology that rendered it "old-fashion". To a certain extent, images remain relevant as witnessed in the number of studies conducted on this medium and its' effectiveness in language teaching retained regardless of teaching instructions. The goal of this review of the multiple usages of images for vocabulary acquisition is to highlight the usefulness of pictures and to serve as a gentle reminder to all concerned that thoughtfully employed, images can be of considerable benefits to learners and teachers as well. 


\section{REFERENCES}

Abdul Razak, N.A.N., \& Md Yunus, M. (2016). Using Action Songs inTeaching Action Words to Young ESL Learners. International Journal of Language Education and Applied Linguistics, 4, 15-24

Adlina Ismail \& Normah Yusof (2018). Malaysian children storybooks as ESL reading materials. International Journal of Education \& Literacy Studies, 6(3), 68-76. https://doi.org/10.7575/aiac.ijels.v.6n.3p.68

Aizan Yaacob \& Annamaria Pinter (2008). Exploring the effectiveness of using big books in teaching primary English in Malaysian classrooms. Malaysian Journal of Learning \& Instruction (MJLI), 5, 1-20

Al-Seghayer, K. (2001). The effect of multimedia annotation modes on L2 vocabulary acquisition: A comparative study. Language Learning and Technology, 5(1), 202-232.

Anderson, R.C. (1971). Encoding processes in the storage and retrieval of sentences. Journal of Experimental Psychology, 91(2), 338-341. https://doi.org/10.1037/h0031833

Armon, J., \& Morris, L. J. (2008). Integrated assessments for ELL. Science and Children, 45(8), 49-53.

Ashrafzadeh, A., \& Nimehchisalem, V. (2015). Vocabulary knowledge: Malaysian tertiary level learners' major problem in summary writing. Journal of language teaching and Research, 6(2), 286-291. https://doi.org/10.17507/j1tr.0602.07

Ausubel, D. (1978). In defense of advance organizers: A reply to the critics. Review of Educational Research, 48(2), 251-257. https://doi.org/10.3102/00346543048002251

Baleghizadeh, S., \& Ashoori, A. (2011). The impact of two instructional techniques on EFL learners' vocabulary knowledge: Flash cards versus word lists. MEXTESOL Journal, $35(2), 1-9$.

Brabham, E. G., \& Lynch-Brown, C. (2002). Effects of teachers' reading-aloud styles on vocabulary acquisition and comprehension of students in the early elementary grades. Journal of Educational Psychology, 94(3), 465-473. https://doi.org/10.1037/00220663.94.3.465

Bruton, A. (2007). Vocabulary learning from dictionary reference in collaborative EFL $\begin{array}{llll}\text { translational } \quad \text { writing. } & \text { System, }\end{array}$ https://doi.org/10.1016/j.system.2007.01.004

Calhoun, E. (1999). Teaching beginning reading and writing with the Picture-Word Inductive Model. Association for Supervision and Curriculum Development, Alexandria (VA), USA.

Carney, R. N. \& Levin, J. R. (2002). Pictorial illustrations still improve students' learning from text. Educational Psychology Review, $14(1), \quad$ 5-26. https://doi.org/10.1023/A:1013176309260

Carpenter, S., \& Olson, K. (2012). Are pictures good for learning new vocabulary in a foreign language? Only if you think they are not. Journal of Experimental Psychology: Learning, Memory, and Cognition, 38(1), 92-101. https://doi.org/10.1037/a0024828

Cohen, M. (2009). The effectiveness of imagery interventions on the vocabulary learning of second grade students. NERA Conference Proceedings 2009, 21-23 Oct, Rocky Hill, Connecticut, USA. 
Cohen, M (2012). Strengthening science vocabulary through the use of imagery interventions with college students. Creative Education, 3(7), 1251-1258. https://doi.org/10.4236/ce.2012.37184

Craik, F., \& Lockhart, R. (1972). Levels of processing: A framework for memory research. Journal of Verbal learning and Verbal Behavior, 11(6), 671-684. https://doi.org/10.1016/S0022-5371(72)80001-X

Craik. F., \&Tulving. E. (1975). Depth of processing and retention of words in episodic memory. Journal of Experimental Psychology: General, 104(3), 268-294. https://doi.org/10.1037/0096-3445.104.3.268

Culyer, R. (1988). Using single concept cards and sentences for affective and Effective reading. Intervention in School \& Clinic, 24(2), 143-152. https://doi.org/10.1177/105345128802400205

Davies, J., Mengersen, K., Bennett, S., \& Mazerolle, L. (2014). Viewing systematic reviews and meta-analysis in social research through different lenses. SpringerPlus, 3(1), 511. https://doi.org/10.1186/2193-1801-3-511

Dodigovic, M. (2013).Vocabulary learning with electronic flashcards: Teacher design vs. student design. Voices in Asia Journal, 1(1), 15-33.

Durso, F. T., \& Johnson, M. K. (1980). The effects of orienting tasks on recognition, recall, and modality confusion of pictures and words. Journal of Verbal Learning and Verbal Behavior, 19(4), 416-429. https://doi.org/10.1016/S0022-5371(80)90294-7

Erten, İ. H., \& Tekin, M. (2008). Effects on vocabulary acquisition of presenting new words in semantic sets versus semantically unrelated sets. System, 36(3), 407-422. https://doi.org/10.1016/j.system.2008.02.005

Ghanaguru, S., Liang, N.H. \& Kit, N. L. (1998). An initial study of reading problems and strategies: A teacher's perspective. IPBA Journal, 3(1), 1-19. Retrieved from http://apps.emoe.gov.my/ipba/rdipba/cd1/article56.pdf

Glasziou, P. (2001). Systematic reviews in health care: A practical guide. New York, NY: Cambridge University Press. https://doi.org/10.1017/CBO9780511543500

Hazita Azman. (2016). Implementation and Challenges of English Language Education Reform in Malaysian Primary Schools. 3L: Language, Linguistics, Literature, 22(3), 65-78. https://doi.org/10.17576/3L-2016-2203-05

Hsiao, T.Y., \& Oxford, R.L. (2002). Comparing theories of language learning strategies: A confirmatory factor analysis. The modern Language Journal, 86 (3), 368-383. https://doi.org/10.1111/1540-4781.00155

Huang, H. L. (2006). The effects of storytelling on EFL young learners' reading comprehension and word recall. English Teaching and Learning, 30(3), 51-74.

Hung, H. T. (2015). Intentional vocabulary learning using digital flashcards. English Language Teaching, 8(10), 107-112. https://doi.org/10.5539/elt.v8n10p107

Iliyasu Hussaini, Lee, M.F., Dikko Suleiman, \& Abba Aji Abubakar (2016). Improving Nigerian and Malaysian primary school students vocabulary skills using flashcards. International Journal of Research and Review (IJRR), 3(7), 19-25.

Jacoby, L. L. (1983). Remembering the data: Analyzing interactive processes in reading. Journal of Verbal Learning and Verbal Behavior, 22(5), 485-508. https://doi.org/10.1016/S00225371(83)90301-8 
Jiang, X. (2014). Vocabulary learning through use of the Picture-Word Inductive Model for young English learners in China: A mixed methods examination using cognitive load theory (Unpublished $\mathrm{PhD}$ thesis). University of Florida, Florida, USA.

Joyce, B., Weil, M., \& Calhoun, E. (2004). Models of teaching (Seventh Edition). Boston: Allyn and Bacon.

Joyce, B., Weil, M., \& Calhoun, E. (2015). Models of teaching (Ninth Edition). Boston: Pearson Education Inc.

Kahana, M. J. (2014). Foundations of human memory. New York, NY: Oxford University Press.

Kirkpatrick, E. A. (1894). An experimental study of memory. Psychological Review, 1(6), 602609. https://doi.org/10.1037/h0068244

Komachali, M. E., \& Khodareza, M. (2012). The effect of using vocabulary flash card on Iranian pre-university students' vocabulary knowledge. International Education Studies, 5(3), 134-147. https://doi.org/10.5539/ies.v5n3p134

Kurniawan, S., \& Andini, T. (2015). Picture Word Inductive Model (PWIM) strategy in writing descriptive paragraph. Jurnal Universitas Islam Riau, 2(2).

Lee, B.C. (2013). A quasi-experimental study on the impact of the Picture Word

Inductive Model on the vocabulary acquisition of year 1 learners in Malaysia. (Unpublished master's thesis). Universiti Sains Malaysia, Malaysia.

Li, X. (2011). The Picture-Word-Inductive Model and English vocabulary acquisition: A study in a Swedish primary school (Master's Thesis, Kristianstad University). Retrieved from http://urn.kb.se/resolve?urn=urn:nbn:se:hkr:diva-8376

McCullough, C. (1955). Flash cards-The opiate of the reading program? Elementary English, 32, 379-381.

McKeown, M. G., \& Beck, I. (2014). Effects of vocabulary instruction on measures of language processing: Comparing two approaches. Early Childhood Research Quarterly, 29(4), 520-530. https://doi.org/10.1016/j.ecresq.2014.06.002

Meena A/P N. Mohan Das (2014). Use of mind-mapping and flashcards in vocabulary development among year 5 students. (Unpublished master's thesis). Universiti Teknologi Malaysia, Kuala Lumpur, Malaysia.

Mondria, J. A., \& Mondria-de Vries, S. (1994). Efficiently memorizing words with the help of word cards and "hand computer": Theory and applications. System, 22(1), 47-57. https://doi.org/10.1016/0346-251X(94)90039-6

Morris, C. D., Bransford, J. D., \& Franks, J. J. (1977). Levels of processing versus transfer appropriate processing. Journal of Verbal Learning and Verbal Behavior, 16(5), 519533. https://doi.org/10.1016/S0022-5371(77)80016-9

Muhamad Zahiri Awang Mat, Siti Salwa Md. Sawari, Noriza Mat Nawi, Faridah Junit \& Mislinah Mohd Othman (2016). An action research on the effectiveness uses of flash card in promoting Hijaiyah literacy among primary school pupils. Mediterranean Journal of Social Sciences (MCSER), 7(2), 433-438. https://doi.org/10.5901/mjss.2016.v7n2s1p433

Nagy, W. E., Anderson, R. C, \& Herman, P. A. (1987). Learning words from Context during normal reading. American Educational Research Journal, 24(2), 237-270. https://doi.org/10.3102/00028312024002237

Nakata, T. (2008). English vocabulary learning with word lists, word cards and computers: Implications from cognitive psychology research for optimal spaced learning. ReCALL, 20(1), 3-20. https://doi.org/10.1017/S0958344008000219 
Nation, I.S. P. (2001). Learning vocabulary in another language. Cambridge, UK: Cambridge University Press. https://doi.org/10.1017/CBO9781139524759

Nation, I. S. P. (2006). Vocabulary: Second language. In K. Brown (Ed.), Encyclopaedia of Language and Linguistics (Second Edition) (pp. 448-454). Oxford: Elsevier. https://doi.org/10.1016/B0-08-044854-2/00635-0

Nelson, D. L. (1979). Remembering pictures and words: Appearance, significance, and name. In L.S. Cermak \& F.I.M. Craik (Eds.), Levels of processing in human memory (pp. 45-76). Hillsdale, NJ: Erlbaum.

Nelson, D. L. \& Brooks, D. H. (1973). Functional independence of pictures and their verbal memory codes. Journal of Experimental Psychology, 98(1), 44-48. https://doi.org/10.1037/h0034299

Nelson, D. L, Brooks, D. H., \& Borden, R. C. (1974). Effects of formal similarity:Phonetic, graphic or both? Journal of Experimental Psychology, 103(1), 91-96. https://doi.org/10.1037/h0036821

Nelson, D. L. \& Reed, V. S. (1976). On the nature of pictorial encoding: A levels-of-processing. Journal of Experimental Psychology: Human Learning and Memory, 2(1), 49-57. https://doi.org/10.1037//0278-7393.2.1.49

Nelson, D. L., Reed, V. S., \& McEvoy, C. L. (1977). Encoding strategy and sensory and semantic interference. Memory and Cognition, 5(4), 462-67. https://doi.org/10.3758/BF03197387

Nelson, D. L., Reed, V. S., \& Walling, J. R. (1976). Pictorial superiority effect. Journal of Experimental Psychology: Human Learning \& Memory, 2(5), 523-528. https://doi.org/10.1037//0278-7393.2.5.523

Nemati, A. (2009). Memory vocabulary learning strategies and long-term retention. International Journal of Vocational and Technical Education, 1(2), 14-24. https://doi.org/10.4314/marang.v20i1.56821

Neuman, S. B., \& Wright, T. S. (2014). The magic of words: Teaching vocabulary in the early childhood classroom. American Educator, 38(2), 4-11.

Nikoopour, J. \& Kazemi, A. (2014). Vocabulary learning through digitized \& non-digitized flashcards delivery. Proceedings of the International Conference on Current Trends in ELT, 98, 1366-1373. https://doi.org/10.1016/j.sbspro.2014.03.554

Nurani, S., \& Rosyada, A. (2017). Implemented PWIM in developing students' communicative competence of SMK Islam Wijaya Kusuma Jakarta. Lingua Cultura, 11(1). 25-30. http://dx.doi.org/10.21512/lc.v11i1.1608

Oxford, R. (1990). Language learning strategies: What every teacher should know. New York: Newbury House.

Oxford, R., \& Crookall, D. (1990). Vocabulary learning: A critical analysis of techniques. TESL Canada Journal, 7(2), 9-30. https://doi.org/10.18806/tesl.v7i2.566

Palka, E. (1988). Using cards to revise and practice language items. ERIC Document 302-093.

Paivio, A. (1971). Imagery and verbal processes. New York: Holt, Rinehart \& Winston.

Paivio, A. D. (1986). Mental representations. New York, NY: Oxford University Press.

Paivio, A. D. (1990). Mental representations: A dual coding approach (Second Edition). New York, NY: Oxford University Press. https://doi.org/10.1093/acprof:oso/9780195066661.001.0001 
Phang, B. L. (2019). Modern versus traditional: Visual aids in the teaching of English vocabulary among Form 1 ESL students (Unpublished master's thesis). Universiti Tunku Abdul Rahman, Perak, Malaysia

Potter, M., \& Faulconer, B. (1975). Time to understand pictures and words. Nature, 253(5491), 437- 438. https://doi.org/10.1038/253437a0

Robbins, C. \& Ehri, L. C. (1994). Reading storybooks to kindergarteners help them learn new vocabulary words. Journal of Educational Psychology, 86(1), 54-64. https://doi.org/10.1037/0022-0663.86.1.54

Roediger, H. L. (1990). Implicit memory: Retention without remembering. American Psychologist, 45(9), 1043-1056. https://doi.org/10.1037/0003-066X.45.9.1043

Roediger, H. L., \& Blaxton, T. A. (1987). Effects of varying modality, surface features, and retention interval on priming in word fragment completion. Memory \& Cognition, 15(5), 379-388. https://doi.org/10.3758/BF03197728

Roediger, H. L., Srinivas, K. \& Weldon, M. S. (1989). Dissociations between implicit measures of retention. In S. Lewandowsky, J. C. Dunn, \& K. Kirsner (Eds.), Implicit memory: Theoretical Issues (pp. 67-84). Hillsdale, NJ: Erlbaum.

Roediger, H. L., Weldon, M. S., \& Challis, B. H. (1989). Explaining dissociations between implicit and explicit measures of retention: A processing account. In H. L. Roediger III \& F. I. M. Craik (Eds.), Varieties of memory and consciousness: Essays in honour of Endel Tulving (pp. 3-41). Hillsdale, NJ: Erlbaum.

Ryan, R. L. (1993). Using pictures in teaching art and other stuff. Retrieved from http://www.mun.ca/educ/faculty/mwatch/vol2/ryan2.html

Sadoski, M., Goetz, E.T., \& Kangiser, S. (1988). Imagination in story response: Relationships between imagery, affect, and structural importance. Reading Research Quarterly, 23(3), 320-336. https://doi.org/10.2307/748045

Schmitt, N. (2008). Review article: Instructed second language vocabulary learning. Language Teaching Research, 12(3), 329 - 363. https://doi.org/10.1177/1362168808089921

Schmitt, N., \& Schmitt, D. (1995). Vocabulary notebooks: Theoretical underpinnings and practical suggestions. ELT Journal, 49(2), 133-143. https://doi.org/10.1093/elt/49.2.133

Shepard, R. N. (1967). Recognition memory for words, sentences, and pictures. Journal of Verbal Learning and Verbal Behavior, 6(1), 156-163. https://doi.org/10.1016/S00225371(67)80067-7

Sol, R. L. (2008). Cognitive psychology. Shanghai: Shanghai people's Publishing house.

Srinivas, K. (1996). Contrast and illumination effects on explicit and implicit measures of memory. Journal of Experimental Psychology: Learning, Memory, and Cognition, 22(5), 1123-1135. https://doi.org/10.1037//0278-7393.22.5.1123

St. John, P., \& Vance, M. (2014). Evaluation of a principled approach to Vocabulary learning in mainstream classes. Child Language Teaching and Therapy, 30(3), 255-271. https://doi.org/10.1177/0265659013516474

Su, M., Thiebaut de Schotten, M., Zhao, J., Song, S., Zhou, W., Gong, G., McBride, C., \& Ramus, F. (2018). Vocabulary growth rate from preschool to school-age years is reflected in the connectivity of the arcuate fasciculus in 14-year-old children. Developmental Science, 21(5), 1-14. https://doi.org/10.1111/desc.12647

Snyder, H. (2019). Literature review as a research methodology: An overview and guidelines. Journal of Business Research (Elsevier), 104, 333-339. https://doi.org/10.1016/j.jbusres.2019.07.039 
Tan, A., \& Nicholson, T. (1997). Flash cards revisited: Training poor readers to read words faster improves their comprehension of text. Journal of Educational Psychology, 8(2), 276-288. https://doi.org/10.1037/0022-0663.89.2.276

Tan, D.A.L. (2016). Investigating guided extensive reading and vocabulary knowledge performance among remedial ESL learners in a public university in Malaysia (Unpublished PhD thesis). Universiti Sains Malaysia, Penang, Malaysia.

Tan, K.E., \& Parimala Chandrasekaran (2014). The use of contextualised storytelling to enhance Malaysian primary school pupils' reading comprehension. The English Teacher, XLIII (2), 79-92

Tang E., \& Nesi, H. (2003). Teaching vocabulary in two Chinese classrooms: school children's exposure to English words in Hong Kong and Guangzhou. Language Teaching Research 7(1), 65-97. https://doi.org/10.1191/13621688031r113oa

Tranfield, D., Denyer, D \& Smart, P. (2003). Towards a methodology for developing evidenceinformed management knowledge by means of systematic review. British Journal of Management 14(3), 207-222. https://doi.org/10.1111/1467-8551.00375

Trivette, C., \& Dunst, C. (2007). Relative effectiveness of dialogic, interactive, and shared reading Instruction. CELL Reviews, 1(2), 1-12.

Tukimin, R. , Yusoff, N. , \& Baharudin, H. (2019). InRA: An imagery technique to improve reading skills of Arabic single vocal "A" alphabets. Creative Education, 10, 1850-1862. https://doi.org/10.4236/ce.2019.108133

Tulving, E. (1979). Relation between encoding specificity and levels of processing. In L. S. Cermak \& F. 1. M. Craik (Eds.), Levels of processing in human memory (pp. 405-428). Hillsdale, NJ: Erlbaum.

Varatharajoo, C. (2016). The effectiveness of morphemic analysis instruction towards ESL students' vocabulary development (Unpublished $\mathrm{PhD}$ thesis). University of Malaya, Malaysia.

Vesely, P., \& Gryder, N. (2007). Teaching Visual Imagery for Vocabulary Learning. Academic Exchange Quarterly, 11(2), 51-55.

Walsh, D., \& Downe, S. (2005). Meta-synthesis method for qualitative research: A literature review. Journal of Advanced Nursing, 50(2), 204 -211. https://doi.org/10.1111/j.13652648.2005.03380.x

Wasik, B. A., \& Bond, M. A. (2001). Beyond the pages of a book: Interactive book reading and language development in preschool classrooms. Journal of Educational Psychology, 93(2), 243-250. https://doi.org/10.1037/0022-0663.93.2.243

Weldon, M. S., \& Roediger, H. L. (1987). Altering retrieval demands reverses the picture superiority effect. Memory \& Cognition, 15(4), 269-280. https://doi.org/10.3758/BF03197030

Yuniati, D. (2015). The effectiveness of Picture Word Inductive Model (PWIM) for teaching recount text (Unpublished bachelor thesis). Universitas Muhammadiyah Purwokerto, Indonesia.

Yurfalah, D. (2014).The use of Picture Word Inductive Model in teaching vocabulary: A study at the seventh grade students of a state junior high school in Cidaun Cianjur (Unpublished master's thesis). Universitas Pendidikan Indonesia, Indonesia.

Zaheidi, Y \& Adbi, M. (2012). The impact if imagery strategy on EFL learners' vocabulary learning. Procedia: Social and Behavioral Sciences, 69, 2264-2272. https://doi.org/10.1016/j.sbspro.2012.12.197 